\title{
The Comparative Study on Compressed Natural Gas (CNG) and Compressed Biomethane Gas (CBG) Fueled in a Spark Ignition Engine
}

\author{
Tanat Limpachoti ${ }^{1}$, and Kampanart Theinnoi ${ }^{1,2, *}$ \\ ${ }^{1}$ College of Industrial Technology, King Mongkut's University of Technology North Bangkok, 1518 Pracharat 1 Road, \\ Wongsawang, Bangsue, Bangkok 10800, Thailand. \\ ${ }^{2}$ Research Centre for Combustion Technology and Alternative Energy (CTAE), Science and Technology Research Institute, King \\ Mongkut's University of Technology North Bangkok, Bangkok 10800, Thailand.
}

\begin{abstract}
Compressed biomethane gas (CBG) is an interesting alternative fuel that can be used to solve fossil fuel crisis problems. Nevertheless, it is concerned about engine performance and exhaust gas emission. In additions, CBG can be produced from agricultural harvesting residues and the food industry that is a good opportunity for utilizing biogas as a vehicle fuel. The aims of this research are comparative analysis of the engine performance and exhaust emission on a CBG and compressed natural gas $(\mathrm{CNG})$ fuelled in a spark ignition engine on engine performance and emissions. The engine has been modified to operate with both fuel gases under constant engine load (50\% maximum load) and engine speed $(1500-3500 \mathrm{rpm})$. The results show that the engine operated with CBG has higher thermal efficiency with lower the nitrogen oxide $\left(\mathrm{NO}_{\mathrm{x}}\right)$ and hydrocarbon (HC) emissions compared with CNG. Thus, the CBG fuel can be used as an alternative fuel to substitute CNG fuel in the spark ignition engine. In additions, the results give the useful information for developed and optimised the engine operated with compression biogas to impact the higher demand of automotive fuels in the future.
\end{abstract}

Keyword. Compressed biogas (CBG), Spark ignition engine, Engine performance, Emission

\section{Introduction}

The scarcity of fossil fuel and the extremely high demand and become an important issue of a national industrial and living. Especially, the fuels that will be used in the automotive sector, which are important role in driving the economy in both production and transportation. Thus, the alternative fuels that will be used to solve this problem should be renewable fuel. In addition, the properties of alternative fuel should be similar efficiency to the fossil fuels. That could be provided the same or better engine performance without modification. Furthermore, fuel has emitted less engine out pollution than the fossil fuel. The automotive pollutions issue is another important factor such as greenhouse gas emissions which damages to the Earth's atmosphere and climate from internal combustion engine. There is exigency discreet to use for conserve fossil fuel and replace it by other alternatives wherever possible.

Nowadays, the CNG generally used as an alternative fuel due to the advantage of $\mathrm{CNG}$ are higher thermal efficiency with lower exhaust gas emissions as compared SI engines fuelling with gasoline fuel. In additions, CNG can obtain significantly lower fuel prices than gasoline fuel. However, the non conservable energy development which affected by natural gas demand are extremely increase while natural gas which existed are decrease that effect to consumed in different applications such as automotive, industrial, power generation, domestic fuel, fertilizer industry, petrochemicals. [1,2]

The biogas commonly known as alternative fuel or renewable fuel, which has been proposed to substitute the fossil fuel to solve that problem due to it have many advantages such as natural gas which commonly used as vehicle fuel. $\mathrm{CBG}$ can be produced from both agriculture and industrial wastes [3]. That can be produced both urban and countryside area [4]. Furthermore, the biogas is suitable fuel for heat and power production [5]. Biogas has high potential to replace natural gas due to $\mathrm{CBG}$ has properties approximately to $\mathrm{CNG}$ [1]. The $\mathrm{CBG}$ compositions mainly consists of methane and carbon dioxide compositions in gas phase. It was compressed and stored in container under high pressure for the vehicles purpose. In fact, biogas has not been widely applied as a renewable substitute for internal combustion engines due to the limitation of biogas properties such as the large number of $\mathrm{CO}_{2}$ concentration, calorific value, flame velocity and flammability are lower when compare with natural gas [6], the metal parts in engines can corrosion which cause by a small percentage of $\mathrm{H}_{2} \mathrm{~S}$ in biogas

* Corresponding author: kampanart.t@ cit.kmutnb.ac.th 
$[4,7]$. Therefore, the retrofit of biogas for better quality that suitable for used in vehicle engine by eliminated carbon dioxide, moisture and other impurities which will adversely affect to engine parts or engine performance [8-10]. Moreover, biomethane could compressed into a tank force as compressed natural gas (CNG) to compressed biomethane gas (CBG) for used as a transport fuel in a $\mathrm{CNG}$ vehicle furthermore that is conveniently to storage and reduce costs to transportation.[4] As mentioned by a series of published theoretical and experimental works, the combustion mechanisms and applications in internal combustion engines which used biogas are concerned thus the multiple operating conditions of engine while used biogas as fuel ought to be immensely studied. [11] The previous research which refer to intensity of emission impact such as Carbon monoxide (CO), Hydrocarbon (HC) and Nitrogen oxides $\left(\mathrm{NO}_{\mathrm{x}}\right)$ that motivate to studies effect of SI engine to emission while used alternatives fuel so as CNG and CBG. [12,13]

In this experimental study will comparative analysis of the engine performance and exhaust gas emission on a compressed biomethane gas (CBG) and compressed natural gas (CNG) fuelled in spark ignition engine. The research will enrich the understanding and provide a practical guide to suitable CBG application.

\section{Experimental}

The TOYOTA model 4A-FE gasoline engine with an eddy-current dynamometer which multi-cylinder engine fixed with test-rig was used in this study with various engine speed (1500, 2000, 2500, 3000, $3500 \mathrm{rpm})$ and fixed an engine load (50\% of maximum load). The engine specification is list in Table 1.

Table 1. Specifications of test engine.

\begin{tabular}{ll}
\hline & Specification \\
\hline Engine series & TOYOTA 4A-FE Spark ignition \\
Engine type & 4 cylinders, in line \\
Displacement & $1,587 \mathrm{cc}$ \\
Bore X Stroke & $81 \times 77 \mathrm{~mm}$ \\
Compression ratio & $9.5: 1$ \\
Maximum output & $100 \mathrm{HP} @ 5,600 \mathrm{rpm}$ \\
Maximum torque & $101 \mathrm{ft} .1 \mathrm{bs} @ 4,400 \mathrm{rpm}$ \\
Valves mechanism & 4 Valves, DOHC, Belt \& Gear Drive
\end{tabular}

The engine is modified to operate with compressed natural gas $(\mathrm{CNG})$ and compressed biomethane gas (CBG). The gas fuel entrains to the engine via multipoint electronically controlled port injection system. The incylinder pressure was recorded using a national instruments data acquisition board that connected through with a Kistler 5018A charge amplifier and a Kistler 6056A pressure transducer (1\% measurement accuracy) mounted flush was installed in the cylinder head. A digital shaft encoder is used to measure the crankshaft position. Thermocouples which measure air, oil, inlet manifold and exhaust temperatures and pressure gauges which fixed at relevant spot are comprise in testrig. In addition to that, Normal engine test bed safety features are comprised. During tested Atmospheric conditions such as humidity, temperature and pressure are monitor. The lay out of the experimental as illustrated in Figure 1.

In this work, the exhaust gas in each operating condition is measured via Horiba model MEXA-584L was used to measure exhaust gas include carbon dioxide, unburned hydrocarbons (NIDR-non-dispersive infrared), and $\mathrm{NO}_{\mathrm{x}}$ (CLD chemiluminescence detection). CBG and CNG gas in this study are commercial fuel in market. Properties of CNG and CBG are showed in Table 2.

Table 2. Properties of CNG and CBG [14].

\begin{tabular}{lll}
\hline Fuel properties & $\mathrm{CNG}$ & $\mathrm{CBG}$ \\
\hline Methane (\%Vol.) & 77.87 & 73.78 \\
Nitrogen (\%Vol.) & 14.88 & 15.99 \\
Carbon dioxide (\% Vol.) & 7.08 & 7.18 \\
Oxigen (\% Vol.) & - & 2.95 \\
Hydrogen (\% Vol.) & - & - \\
Hydrogen sulfide $\left(\mathrm{mmg} / \mathrm{m}^{3}\right)$ & - & - \\
Heating value (KJ/kg) & 31.59 & 28.98 \\
Density $\left(\mathrm{kg} / \mathrm{cm}^{3}\right) \mathrm{at} 1 \mathrm{~atm}$ & 0.8014 & 0.7593 \\
Wobbe number $\left(\mathrm{MJ} / \mathrm{m}^{3}\right)$ & $41.9-44$ & $40-41$ \\
\hline
\end{tabular}

\section{Results and discussion}

\subsection{The effect of CBG and CNG on engine performance}

\subsubsection{The effect of engine speed on in-cylinder peak pressure}

The in-cylinder pressure during combustion from engine fuelling with CNG and CBG as main fuel are shown in Fig. 2 and Fig. 3. The higher engine speed led to the incylinder pressure are increased for both fuels. Due to the gas fuels are injected with high concentration to produce the power for engine. The pressure in combustion chamber was dropped under $3000 \mathrm{rpm}$ for CNG combustion however, it has no significant effect on engine using with CBG. That could be the engine is not optimise setup to operate with gas fuel. Thus, the optimisation is required for the engine to provide better performance when operated with CNG and CBG fuel. 


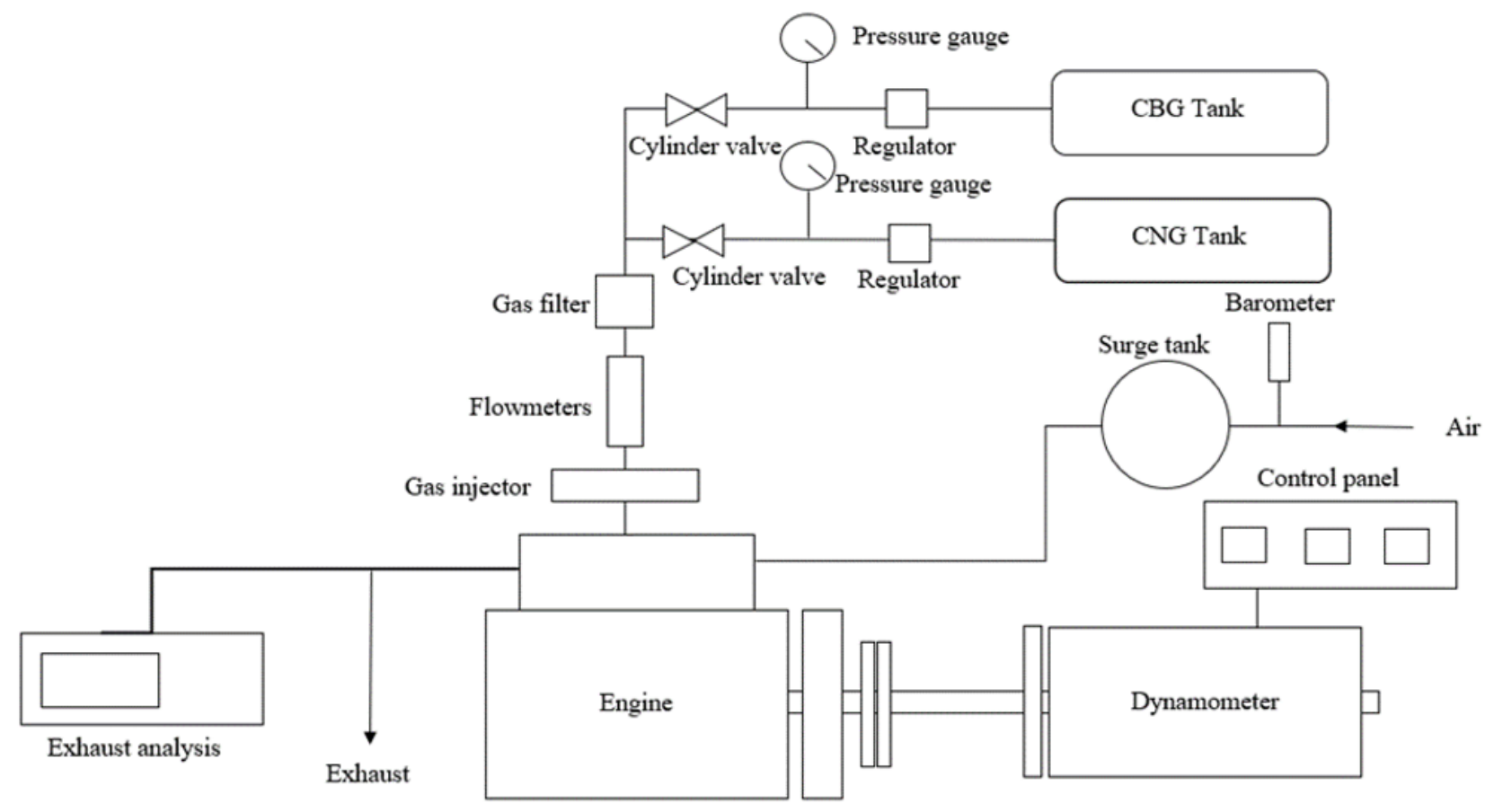

Fig. 1. Schematic diagram of experimental test setup.

The comparison of in cylinder peak pressure by using $\mathrm{CNG}$ and $\mathrm{CBG}$ as shown in Fig.4. The in-cylinder pressure are increased with the higher engine speed, however the in-cylinder peak pressure of CBG fuel is lower than $\mathrm{CNG}$ fuel at various engine speeds that mainly due to the $\mathrm{CNG}$ density is higher than the $\mathrm{CBG}$ as shown in Table 2. The fuel density effected to the fuel mass fraction inside the combustion chamber due to the higher density can be produce the high burning rated of fuel, including shown high temperature during the ignition phase that resulted to higher in-cylinder pressure [15].

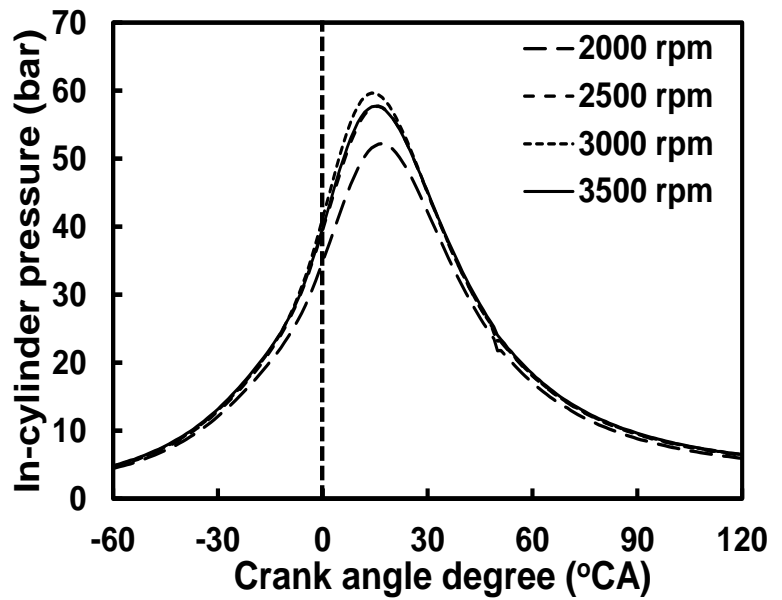

Fig. 2. The effect of engine speed on in-cylinder pressure from combustion of CNG fuelling.

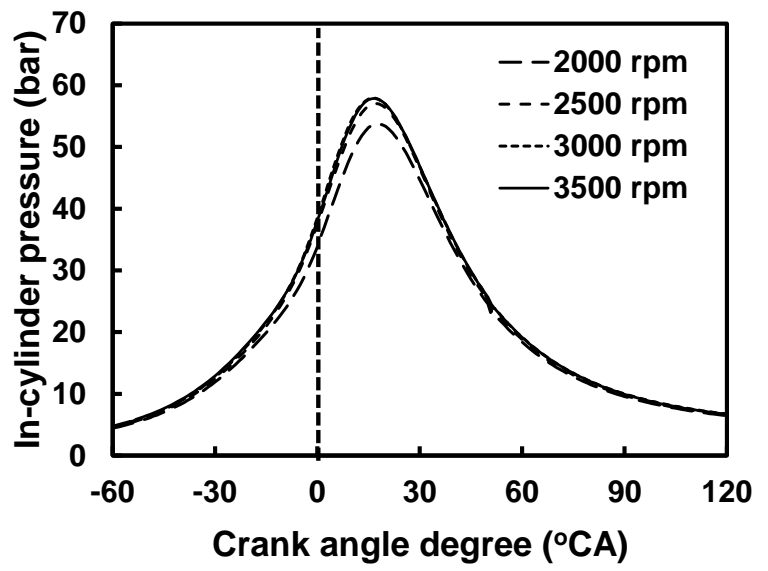

Fig. 3. The effect of engine speed on in-cylinder pressure from combustion of CBG fuelling.

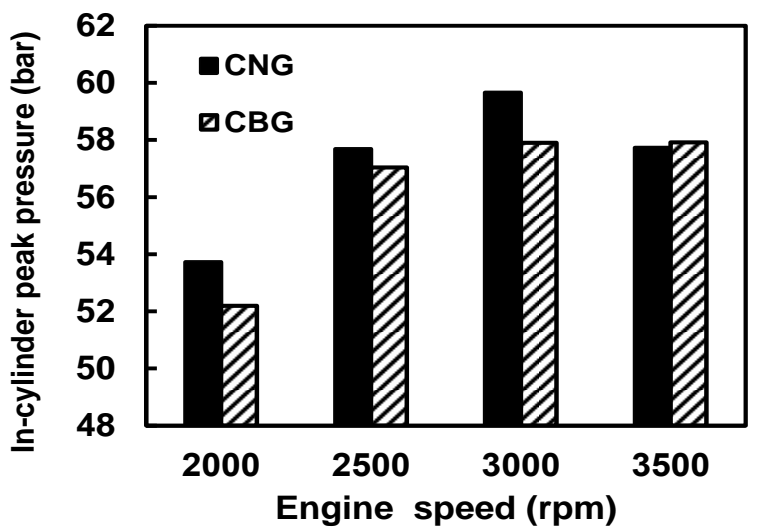

Fig. 4. The effect of engine speed on In-cylinder peak pressure from combustion of $\mathrm{CBG}$ and $\mathrm{CNG}$ fuelling. 


\subsubsection{The effect of engine speed on exhaust gas temperature}

The effect of engine speed on exhaust gas temperature from combustion of CNG and CBG as show in Fig.5. The exhaust gas temperature that increases respectively as increases engine speed both used CNG and CBG. Moreover the engine was running using the $\mathrm{CBG}$, exhaust gas temperature was lower than using CNG throughout the engine speed That can be explained by that result to flame propagation speed of the CNG which slower than CBG provided the combustion to conduct until the end of the expansion stroke that raised the exhaust gas temperature for the CNG operation.[16]

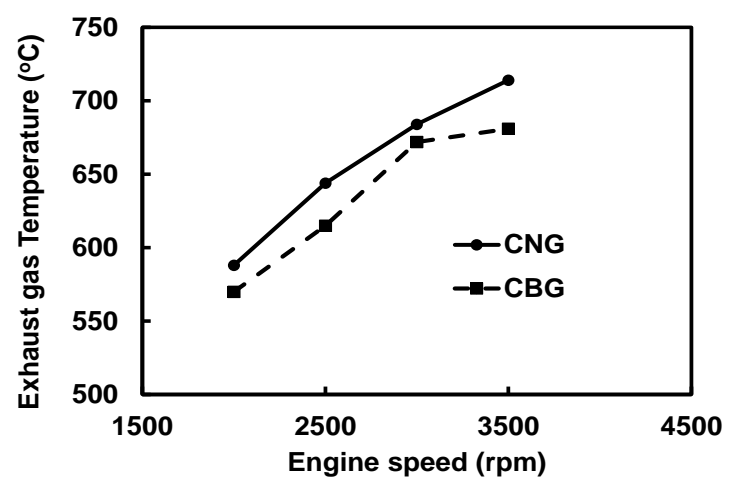

Fig 5. Exhaust gas temperature in various engine speed while used $\mathrm{CNG}$ and $\mathrm{CBG}$ as fuel.

\subsubsection{The effect of engine speed on engine brake power}

The effect of engine speed to engine brake power both using the CBG and the CNG as fuel show in Fig. 6. The brake power are increased with higher engine speed for $\mathrm{CNG}$ and CBG fuelling in the engine. Moreover, the engine was fuelled with CBG gas shown lower brake power compared with the engine fuelling with CNG. In order to the higher methane $\left(\mathrm{CH}_{4}\right)$ contents in $\mathrm{CNG}$ fuel compositions [15] as shown in table 1. The high heating value also dominated for higher brake power compared with CBG. However, that can observe the brake power in each engine speed has shown no significant effect for both fuels.

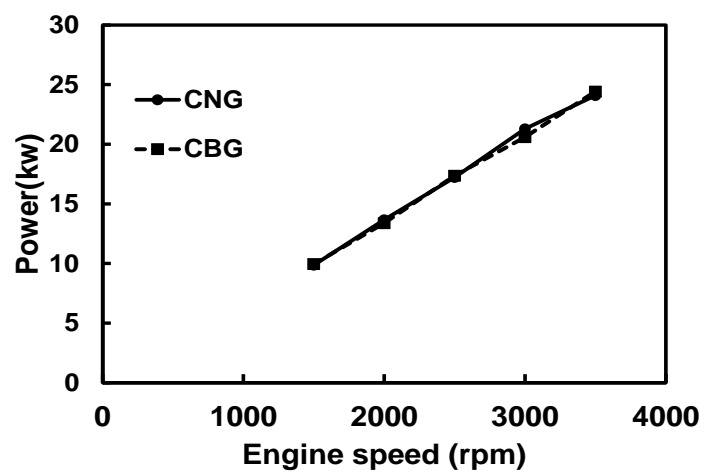

Fig. 6. Effect of engine speed when using $\mathrm{CNG}$ and $\mathrm{CBG}$ as fuel on the brake power output.

\subsubsection{The effect of engine speed on brake specific fuel consumption.}

The variation of brake specific fuel consumption (BSFC) in the engine speed between 1500 to $3500 \mathrm{rpm}$ under constant engine load as shown in Fig.7. BCG has low heating value lead to show the higher BSFC for all engine speed compared to CNG. In addition, CBG shows high burning rate compare to CNG [16]. The overall of BSFC are respectively decreases with higher engine speed both CNG and CBG fuel that is mainly due to the higher heat loss from combustion chamber to chamber walls.

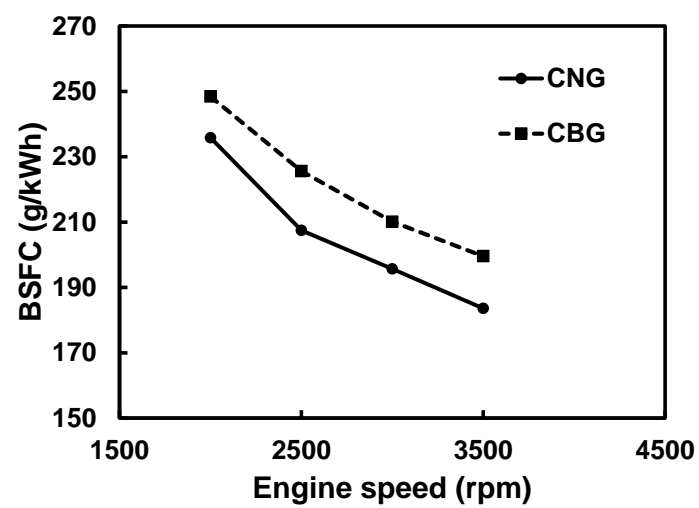

Fig. 7. Effect of engine speed when using $\mathrm{CNG}$ and $\mathrm{CBG}$ as fuel to Brake specific fuel consumption.

\subsubsection{The effect of engine speed on brake thermal efficiency}

The brake thermal efficiency (BTE) of SI engine was used CNG and CBG as fuel in various engine speeds that show in Fig.8. The engine fueled with CNG was shown the lower BTE than using CBG which mainly due to CBG have oxygen content which effect to provides better combustion performance. In additions, CBG has shown the faster laminar flame propagation and higher heat release rate in properties [17], However the higher engine speed $(2500 \mathrm{rpm})$ has no significant effect on BTE for both CNG and CBG fuel.

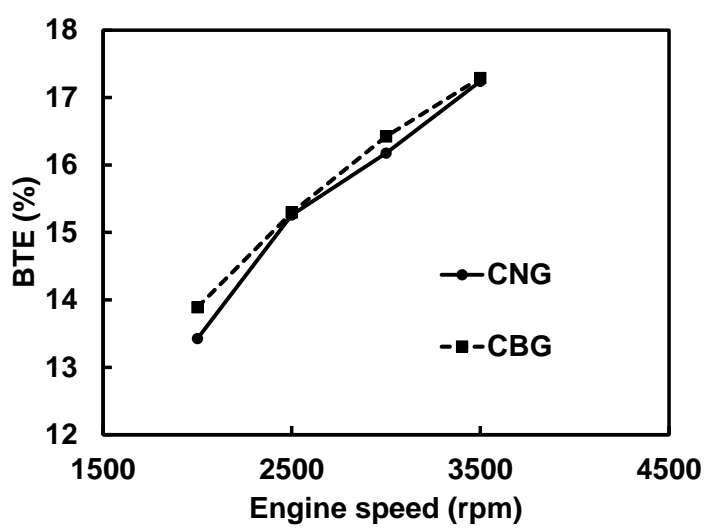

Fig. 8. Effect of engine speed when using $\mathrm{CNG}$ and $\mathrm{CBG}$ as fuel on brake thermal efficiency. 


\subsection{The effect of CNG and CBG on exhaust gas emissions}

\subsubsection{Carbon monoxide (CO) emission}

$\mathrm{CO}$ emission while used $\mathrm{CNG}$ and $\mathrm{CBG}$ as fuel in various engine speeds as shown in Fig.9. The $\mathrm{CO}$ concentration is decreases respectively with higher engine speed. Furthermore, CNG has less $\mathrm{CO}$ emission than CBG mainly due to the higher combustion temperature was reason of the low $\mathrm{CO}$ emission cause by the $\mathrm{CO}$ will converts to $\mathrm{CO}_{2}$. The result are matched with Fig.5. CNG can be combustible than the CBG, which effected $\mathrm{CNG}$ has lower $\mathrm{CO}$ emission than $\mathrm{CBG}$ [16].

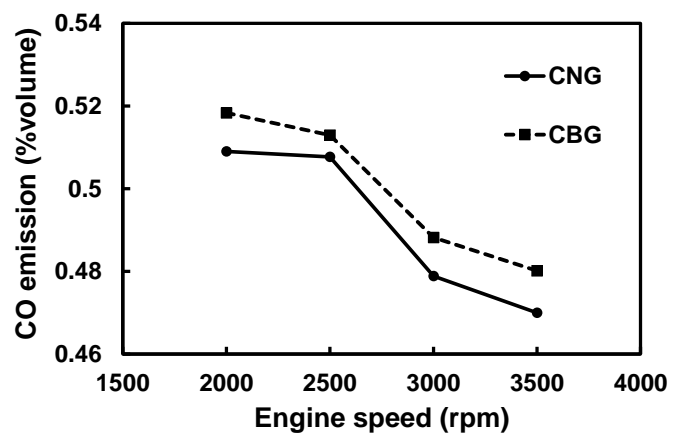

Fig. 9. The effect of engine speed on carbon monoxide concentration from combustion of $\mathrm{CNG}$ and $\mathrm{CBG}$ fuelling.

\subsubsection{Hydrocarbon (HC) emission}

The hydrocarbon emission of $\mathrm{CNG}$ and $\mathrm{CBG}$ are reduced with increases engine speed as seen in Fig.10. The engine was operated with CBG show the lower amount of $\mathrm{HC}$ emission emitted in exhaust gas than fuelling with $\mathrm{CNG}$ due to the formation of unburnt hydrocarbon (UBHC) during incomplete combustion under mixing between air and fuel (rich or lean mixture). CNG show higher $\mathrm{HC}$ emission than CBG especially in low engine speed due to poor oxidation of unburnt hydrocarbon (UBHC) during the warm-up period [1]. However, the high engine speed ( $>3000 \mathrm{rpm}$ ) found that the $\mathrm{HC}$ emission level of CBG is usually matched tend of $\mathrm{CNG}$ that has no significant effect on higher engine speed.

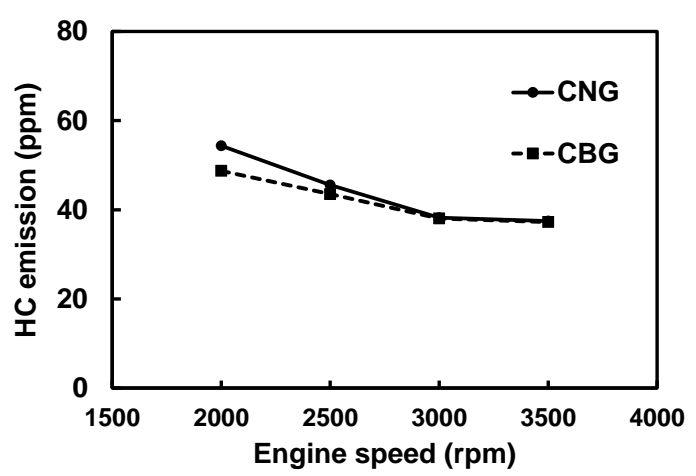

Fig. 10. The effect of engine speed on hydrocarbon concentration emissions from combustion of $\mathrm{CNG}$ and $\mathrm{CBG}$ fuelling.

\subsubsection{Nitrogen oxides $\left(N O_{x}\right)$ emission}

NOx concentration from combustion of CNG and CBG fuelling under various engine speeds shown in Fig.11. The overall $\mathrm{NO}_{\mathrm{x}}$ emission from both fuels increases with higher engine speed. The combustion of CBG fuel resulted in substantial reduction of $\mathrm{NO}_{\mathrm{x}}$ compared to CNG fuel due to CNG has better combustion, as seen in peak cylinder pressure of $\mathrm{CNG}$ are higher compared with CBG $[16,18]$. In additions, the thermal $\mathrm{NO}_{x}$ is generally generated from high temperature (high in-cylinder pressure) in engine were significantly reduced in the exhaust from the combustion of CNG. In additions, CNG was reduced the formation rate of $\mathrm{NO}_{\mathrm{x}}$ after engine speed 3,000 rpm, however the $\mathrm{NO}_{\mathrm{x}}$ concentration from the combustion of CBG was not significantly reduced among measured, with high engine speed.

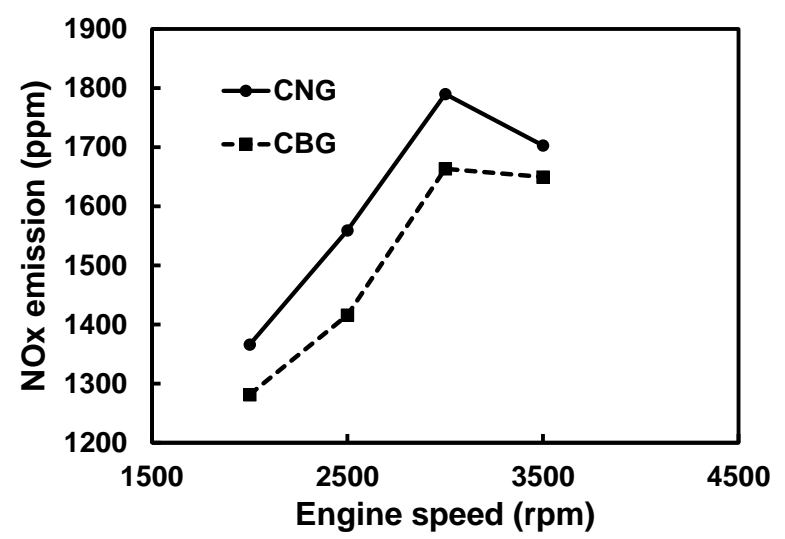

Fig. 11. The effect of engine speed on nitrogen oxides concentration emissions from combustion of $\mathrm{CNG}$ and $\mathrm{CBG}$ fuelling.

\section{Conclusions}

The comparison study between CBG and CNG have been shown to alternative fuel for spark ignition engine to unlock potential performance synergies in the fuel properties, improving the engine performance with low $\mathrm{NO}_{\mathrm{x}}$ emission. The engine fueling with $\mathrm{CBG}$ produces higher BSFC and BTE compared to those of CNG. In additions, the use of CBG show lower brake power than the CNG but there are not significantly different range. In terms of exhaust gas emission found that CBG dramatically released lower $\mathrm{HC}$ and NOx emission than CNG fuel under higher engine speed. In additions, NOx concentration from combustion of CBG fuel are emitted evidently less than $\mathrm{CNG}$ whereas $\mathrm{CNG}$ released obviously lower $\mathrm{CO}$ emission than CBG fuel.

The CBG is one of alternative fuel that impact to spark ignition engines and can be used for substituted CNG. In additions, $\mathrm{CBG}$ can be reduce $\mathrm{HC}$ and $\mathrm{NO}_{\mathrm{x}}$ emission levels. Therefore, the design of CBG in spark ignition engine presented in this work could be considered as giving an engine performance with environmental benefits. However, the optimising engine operation such as fuel injection strategy, EGR additions 
and turbocharger) to improve engine performance and efficiency with CBG fuelling SI engine.

\section{Nomenclature}

Abbreviation

$\begin{array}{ll}\text { BSFC } & \text { Brake specific fuel consumption } \\ \text { BTE } & \text { Brake thermal efficiency } \\ \text { CBG } & \text { Compressed biomethane gas } \\ \mathrm{CH}_{4} & \text { Methane } \\ \mathrm{CLD} & \text { Chemiluminescence detection } \\ \mathrm{CNG} & \text { Compressed natural gas } \\ \mathrm{CO} & \text { Carbon monoxide } \\ \mathrm{CO}_{2} & \text { Carbon dioxide } \\ \mathrm{HC} & \text { Hydrocarbon } \\ \mathrm{NIDR} & \text { Non-dispersive infrared } \\ \text { NO } & \text { Nitrogen oxides } \\ \text { SI } & \text { Spark ignition } \\ \text { UBHC } & \text { unburnt hydrocarbon }\end{array}$

\section{References}

1. K.A. Subramanian, V.C. Mathad, V.K. Vijay, P.M.V. Subbarao, Comparative evaluation of emission and fuel economy of an automotive spark ignition vehicle fuelled with methane enriched biogas and CNG using chassis dynamometer. Applied Energy, 105 (2013): 17-29

2. C. Jury, E. Benetto, D. Koster, B Schmitt, J. Welfring, Life cycle assessment of biogas production by monofermentation of energy crops and injection into the natural gas grid. Biomass Bioenergy, 34, 1 (2010):54-66.

3. J.B. Holm-Nielsen, T. Seadi A.L., P. OleskowiczPopiel, The future of anaerobic digestion and biogas utilization. Bioresource Technology, 100 (2009), 5478-5784.

4. D. Deublein, A. Steinhauser, Biogas from Waste and Renewable Resources: An Introduction. Wiley$\mathrm{VCH}$ Verlag $\mathrm{GmbH}$ \& $\mathrm{Co} \mathrm{KGaA}$, Weinheim, Germany (2008)

5. M. Larsson, S. Grönkvist and P. Alvfors, Upgraded biogas for transport in Sweden : effects of policy instruments on production, infrastructure deployment and vehicle sales, Journal of Cleaner Production, 112 (2016): 3774-3784.

6. E. Porpatham, A. Ramesh, B. Nagalingam, Effect of compression ratio on the performance and combustion of a biogas fuelled spark ignition engine, Fuel, 95 (2012): 247-256.
7. E. Porpatham, A. Ramesh, B. Nagalingam, Investigation on the effect of concentration of methane in biogas when used as a fuel for a spark ignition engine, Fuel, 87 (2008): 1651-1659.

8. N. Dussadee, K. Reansuwan, R. Ramaraj, Potential development of compressed bio-methane gas production from pig farms and elephant grass silage for transportation in Thailand, Bioresource Technology, 155 (2014): 438-441.

9. A. Demirbas, Political economic and environmental impacts of biofuels: a review, Applied Energy, 86 (2009): 108-117.

10. N. Johansson, Production of liquid biogas, LBG, with cryogenic and conventional upgrading technology, Lund Institute of Technology (2008)

11. Q. Yong, S. Shuzhou, J. Dehao, S. Xinxing, L. Xingcai , Review of the state-of-the art of biogas combustion mechanisms and applications in internal combustion engines, Renewable and Sustainable Energy Reviews, 69 (2017): 50-58.

12. R. Janta, K. Sekiguchu, R. Yamaguchi, K. Sopajaree, B. Plubin, T. Chetiyanukornkul, Spatial and Temporal Variations of Atmospheric PM10 and Air Pollutants Concentration in Upper Northern Thailand During 2006-2016, Applied Science and Engineering Progress 13, 3 (2020): 256-267

13. S.N.K. Reddy, M.M. Wani, A Comprehensive Review on Effects of Nanoparticles-Antioxidant Additives-Biodiesel Blends on Performance and Emissions of Diesel Engine, Applied Science and Engineering Progress, 13, 4 (2020): 285-298

14. A. Santiarpa, T. Wongchang, B. Sawatmongkhon, K. Theinnoi, C. Chaitongrat, Impact of Compressed Biogas on Combustion and Exhaust Emission Characteristic from Spark Ignition Engine, 2018 Third International Conference on Engineering Science and Innovative Technology (ESIT), (2018): 1-4, doi: 10.1109/ESIT.2018.8665329.

15. M.M. Tahir, M. S. Ali, M.A. Salim, R.A. Bakar, A.M. Fudhail, M.Z. Hassan, M.S. Abdul Muhaimin, Performance analysis of a spark ignition engine using compressed natural gas (CNG) as fuel.

16. M.I. Jahirul, H.H. Masjuki, R. Saidur, M.A. Kalam, M.H. Jayed, M.A. Wazed, Comparative engine performance and emission analysis of $\mathrm{CNG}$ and gasoline in a retrofitted car engine, Applied Thermal Engineering, 30 (2010): 2219-2226

17. C. Jung, J. Park, S. Song, Performance and NOx emissions of a biogas-fueled turbocharged internal combustion engine, Energy, 86 (2015): 186-195

18. J.B. Heywood, Internal combustion engine Fundamental, Automotive Technology Series, (1998). 